University of Nebraska - Lincoln

DigitalCommons@University of Nebraska - Lincoln

2008

\title{
TATA-Binding Protein Recognition and Bending of a Consensus Promoter Are Protein Species Dependent
}

\author{
JoDell E. Whittington \\ University of Nebraska - Lincoln \\ Roberto F. Delgadillo \\ University of Nebraska - Lincoln \\ Torrissa J. Attebury \\ University of Nebraska - Lincoln \\ Laura K. Parkhurst \\ University of Nebraska - Lincoln \\ Margaret A. Daugherty \\ Middlebury College
}

See next page for additional authors

Follow this and additional works at: https://digitalcommons.unl.edu/chemistryparkhurst

Part of the Chemistry Commons

Whittington, JoDell E.; Delgadillo, Roberto F.; Attebury, Torrissa J.; Parkhurst, Laura K.; Daugherty, Margaret A.; and Parkhurst, Lawrence J., "TATA-Binding Protein Recognition and Bending of a Consensus Promoter Are Protein Species Dependent" (2008). Lawrence Parkhurst Publications. 6.

https://digitalcommons.unl.edu/chemistryparkhurst/6

This Article is brought to you for free and open access by the Published Research - Department of Chemistry at DigitalCommons@University of Nebraska - Lincoln. It has been accepted for inclusion in Lawrence Parkhurst Publications by an authorized administrator of DigitalCommons@University of Nebraska - Lincoln. 


\section{Authors}

JoDell E. Whittington, Roberto F. Delgadillo, Torrissa J. Attebury, Laura K. Parkhurst, Margaret A.

Daugherty, and Lawrence J. Parkhurst 
Note: The American Chemical Society, publishers of this article, permit the archiving of only the abstract, tables, and figures from their publications. The full text of this article has been deposited with NIH PubMed Central and will appear there soon. $[3 / 22 / 2010]$

Published in Biochemistry 47 (2008), pp. 7264-7273; doi: 10.1021/bi800139w Copyright (C 2008 American Chemical Society.

The work described in this article was supported by NIH Grants GM59346 and RR015468.

\title{
TATA-Binding Protein Recognition and Bending of a Consensus Promoter Are Protein Species Dependent
}

\author{
JoDell E. Whittington, ${ }^{1}$ Roberto F. Delgadillo, ${ }^{1}$ Torrissa J. Attebury, ${ }^{1}$ Laura K. Parkhurst, ${ }^{1}$ \\ Margaret A. Daugherty, ${ }^{2}$ and Lawrence J. Parkhurst ${ }^{1}$ \\ 1. Department of Chemistry, University of Nebraska-Lincoln, Lincoln, Nebraska 68588-0304 \\ 2. Department of Chemistry and Biochemistry, Middlebury College, Middlebury, Vermont 05753 \\ Corresponding author - L. J. Parkhurst, tel 402 472-3316, fax 402 472-2044, e-mail lparkhurst1@unl.edu
}

\begin{abstract}
The structure and behavior of full-length human TBP binding the adenovirus major late promoter (AdMLP) have been characterized using biophysical methods. The human protein induces a $97^{\circ}$ bend in $\mathrm{DNA}_{\mathrm{AdMLP}}$. The high-resolution functional data provide a quantitative energetic and kinetic description of the partial reaction sequence as native human TBP binds rapidly to a consensus promoter with high affinity. The reaction proceeds with successive formation of three bound species, all having strongly bent DNA, with the concurrence of binding and bending demonstrated by both fluorescence and anisotropy stopped flow. These results establish the protein species dependence of the TBP-DNA $A_{\text {AdMLP }}$ structure and recognition mechanism. Additionally, the strong correlation between the DNA bend angle and transcription efficiency demonstrated previously for yeast TBP is shown to extend to human TBP. The heterologous $\mathrm{NH}_{2}$-terminal domains are the apparent source of the species-specific differences. Together with previous studies the present work establishes that $\mathrm{TBP}_{\mathrm{wt}}-\mathrm{DNA}_{\mathrm{TATA}}$ function and structure depend both on the TATA box sequence and on the TBP species.
\end{abstract}

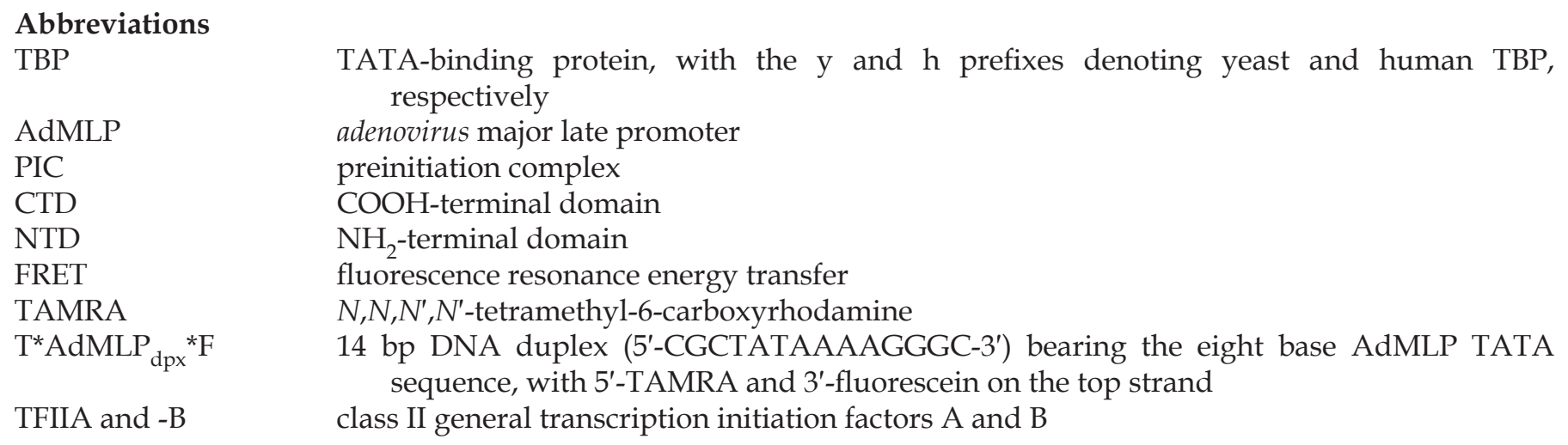


Table 1. Optimal Rate Constants and Corresponding Enthalpy and Entropy Changes for $h$ TBP-DNA ${ }_{\text {AdMLP }}$ Partial Reaction Steps in Accord with Equation 2 Together with Relative Quantum Yields for Each of the Three Bound Species

\begin{tabular}{llll}
\hline$i^{\mathrm{a}}$ & \multicolumn{1}{c}{$k_{i}\left(\mathrm{~s}^{-1}\right)$} & $\Delta H_{i}^{\circ \ddagger}\left(\mathrm{kcal} \mathrm{mol}^{-1}\right)$ & $\Delta S_{i}^{\circ \ddagger}\left(\mathrm{cal} \mathrm{K}^{-1} \mathrm{~mol}^{-1}\right)^{\mathrm{c}}$ \\
\hline 1 & $5.5(5.2,5.6)^{\mathrm{b}} \mu \mathrm{M}^{-1}$ & $7.4(6.2,8.6)$ & $-4.3(-8.5,-0.3)$ \\
2 & $2.75(2.6,3.1)$ & $3.0(3.0,4.1)$ & $-48(-52,-45)$ \\
3 & $0.41(0.39,0.43)$ & $9.5(7.4,11)$ & $-30(-37,-23)$ \\
4 & $0.017(0.013,0.022)$ & $3.2(3.0,4.9)$ & $-58(-63.5,-52)$ \\
5 & $0.045(0.025,0.066)$ & $26(22,28)$ & $23(8.4,38)$ \\
6 & $0.022(0.018,0.026)$ & $9.2(6.1,12)$ & $-37(-47,-26)$ \\
$\mathrm{QYI}_{1}$ & $0.52(0.42,0.59)$ & & \\
$\mathrm{QYI}_{2}$ & $0.52(0.49,0.54)$ & & \\
$\mathrm{QY}_{\text {final }}$ & $0.52(0.49,0.54)$ & & \\
\hline
\end{tabular}

a The values shown are at $20^{\circ} \mathrm{C}$ and $1 \mathrm{M}$ standard state for each step, $i$, along the reaction pathway. The assumption was made that $\Delta C_{p}^{\ddagger}=0$; therefore, there is no temperature dependence for $\Delta H_{i}^{\circ \ddagger}$ or $\Delta S_{i}^{\circ \ddagger}$.

$\mathrm{b}$ Parameter errors, which derive from a joint confidence region, were obtained in the following manner: the $15 \times 15$ variance matrix was calculated from the inverse of the approximate Hessian matrix following the method of Bard (44), using a $1 \%$ change in the various parameters to calculate the required partial derivatives. The partial derivatives were taken over 50 time points for each of the 10 kinetic curves and over 50 fractional saturation points for each of the 3 binding curves. In other studies, we have used simulated noisy data with appropriately scaled random noise that corresponded to the experimental errors to obtain the distribution of fitted parameters, a widely recommended and common procedure (45). That approach yields results that are in excellent agreement with a third approach: knowing the global optimum from 25 random starting positions in parameter space, the 25 sets of parameter values obtained when the Simplex search crossed the $68 \%$ joint confidence boundary were used to obtain the distribution of parameter values. The latter two procedures provided estimates that were not dependent on an assumed hyperelliptical joint confidence region. The reported parameter error estimates are averages of those obtained from the variance matrix and the latter procedure employing the joint confidence boundary. Despite the care taken in determining the error estimates, these values must be considered with caution since they are the extreme limits for each individual parameter as projections of the joint confidence region onto a given parameter axis. Because the volume of the joint confidence region is markedly less than that of the hyperrectangle described by all of the parameter errors (46), one cannot assume that any parameter vector with projections jointly within the error estimates provides an adequate description of the data. Rather, the valid values are those that adequately represent the satisfactory fits to the experimental data based on the reduced $\chi^{2}$ values for the stopped flow and relaxation curves of 0.015 and 0.025 (normalized from 1 to 0 ) and an average $6 \%$ error for the equilibrium constant.

c $\Delta S_{i}^{\circ \ddagger}$ values were calculated from $k_{i}$ and $\Delta H_{i}^{\circ \ddagger}$ using transition state theory. 

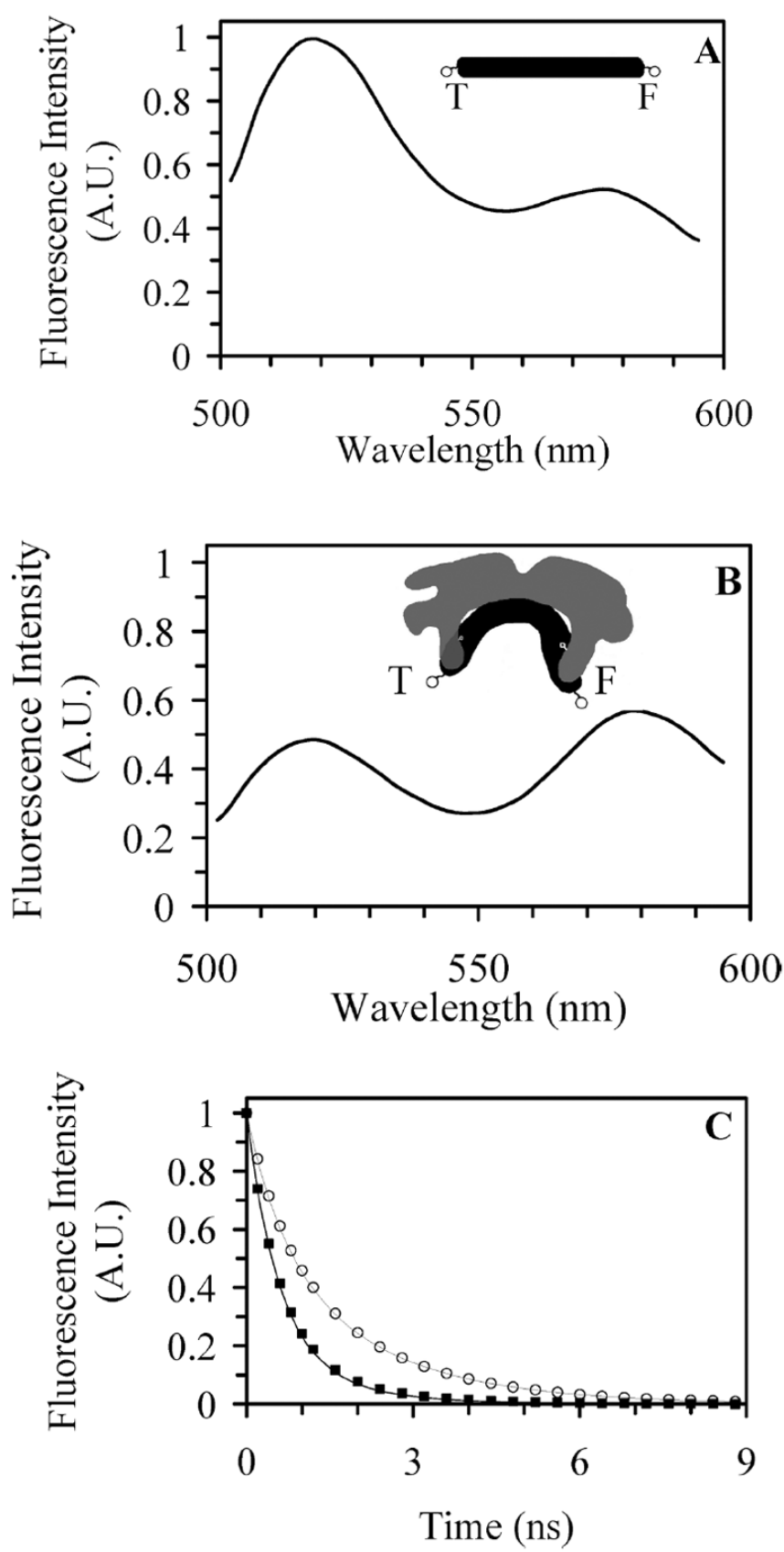

Figure 1. Donor fluorescein emission in the steady state (A) and resolved in the ns time regime ( $C$, upper curve) for unbound $\mathrm{T}^{*} \mathrm{AdMLP} \mathrm{dpx}^{*} \mathrm{~F}$ and the corresponding spectra following human TBP binding (B and C, lower curve). The relatively straight and rigid unbound duplex maintains maximum separation of the 3' FRET donor, fluorescein (F, $518 \mathrm{~nm}$ peak), and the 5' acceptor, TAMRA (T, $578 \mathrm{~nm}$ peak). (A) Since the rate of energy transfer from donor to acceptor depends on the inverse sixth power of the distance between these dyes, the intensity of the fluorescein emission peak is high: the excited state fluorescein population relaxes back to the ground state primarily by photon emission rather than by the transfer of energy to the TAMRA population. (B) $h$ TBP binding and bending result in a much decreased interdye distance, greatly increasing the efficiency of energy transfer and thus decreasing the donor emission. We have shown previously that both the labeled duplex and the protein are stable for at least $1 \mathrm{~h}$ under our solution conditions with no measurable change in the spectra over that time period (22). (C) The upper decay curve was generated using the free duplex and is the time-resolved counterpart of (A) with a 1.49 ns average donor lifetime. The increased transfer rate following proteininduced bending shortens the lifetime of the observed fluorescein emission (lower curve) to yield the time decay equivalent of (B) and a 0.726 ns average donor lifetime. The protein activity was determined as described to be $26 \%$. 

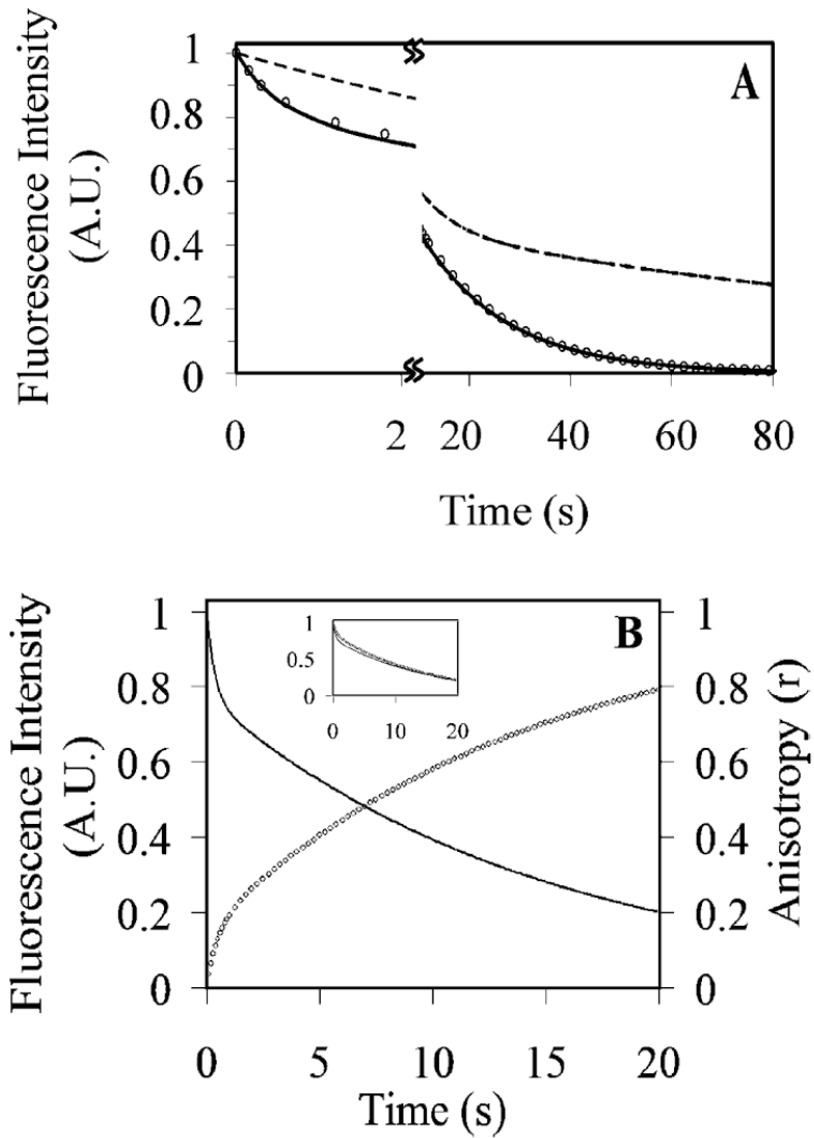

Figure 2. Normalized fluorescence stopped flow kinetics curves of $\boldsymbol{h T B P}$ associating with $\mathrm{T}^{*} \mathrm{AdMLP}{ }_{\mathrm{dpx}}{ }^{*} \mathrm{~F}$ (observed, open circles, and calculated, solid line) compared to the corresponding $y$ TBP reaction (broken line, panel A) and in panel B to the $h \mathrm{TBP}-\mathrm{AdMLP}$ anisotropy stopped flow kinetics trace (open circles). Shown are the time-dependent changes in the donor fluorescein emission as the $\mathrm{T}^{*} \mathrm{AdMLP}_{\mathrm{dpx}}{ }^{*} \mathrm{~F}$ population binds to human and yeast TBP, with the time axis interrupted to clarify the differences (panel A). Although both interactions are biphasic, the human protein binds with an initial relatively very fast phase not seen with the yeast protein and reaches completion significantly faster than does $y$ TBP. Additionally, this fast phase accounts for only $10-22 \%$ of the total amplitude change observed with $h \mathrm{TBP}$ with these conditions, whereas the faster eigenvalue dominates the $y \mathrm{TBP}$ reaction, with the corresponding amplitude ranging from $52 \%$ to $75 \%$ of the overall change. This difference arises because the equilibrium in the first partial $h \mathrm{TBP}$ reaction is strongly toward dissociation, overwhelming the contribution of $k_{3}$ and yielding a much less stable complex than with $y$ TBP. The curves shown for both proteins were obtained using $109 \mathrm{nM}$ protein reacting with $20 \mathrm{nM}$ duplex at $15{ }^{\circ} \mathrm{C}$. The $h \mathrm{TBP}$ experiments were conducted identically to those using $y \mathrm{TBP}$ except for the presence of $10 \%$ glycerol in the $h \mathrm{TBP}$ buffer, shown previously to have no effect on $y \mathrm{TBP}$ kinetics (22). The $y \mathrm{TBP}$ association curve was constructed for identical conditions using previously collected data (18). The $h$ TBP-DNA ${ }_{\text {AdMLP }}$ reaction monitored by stopped flow fluorescence anisotropy (open circles, panel B) is compared with the corresponding stopped flow FRET curve (solid line, panel B). The former was obtained using T*AdMLP ${ }_{\mathrm{dpx}}$, with the normalized change in anisotropy $(r)$ equal to $\left(r_{t}-r_{0}\right) /\left(r_{\infty}-r_{0}\right)$ and is the average of five replicate curves. Both traces are biphasic and show clearly the initial fast phase reflecting ${ }^{\mathrm{h}} \mathrm{I}_{1}$ formation. Because the TAMRA emission changes only slightly, the anisotropy change accurately tracks the kinetics of any process yielding a change in rotational correlation time of the labeled oligonucleotide, which in this case is $h \mathrm{TBP}-\mathrm{DNA}_{\mathrm{AdMLP}}$ binding. Replacing the numerator of the above anisotropy expression with $\left(r_{\infty}-r_{t}\right)$ shows that the two processes are proceeding in tandem (inset), confirming the concurrence of DNA binding and bending. The average signal/noise at $t_{1 / 2}$ was $\sim 86$ for the FRET data and $\sim 8$ for the anisotropy data; the two curves agree within error. 


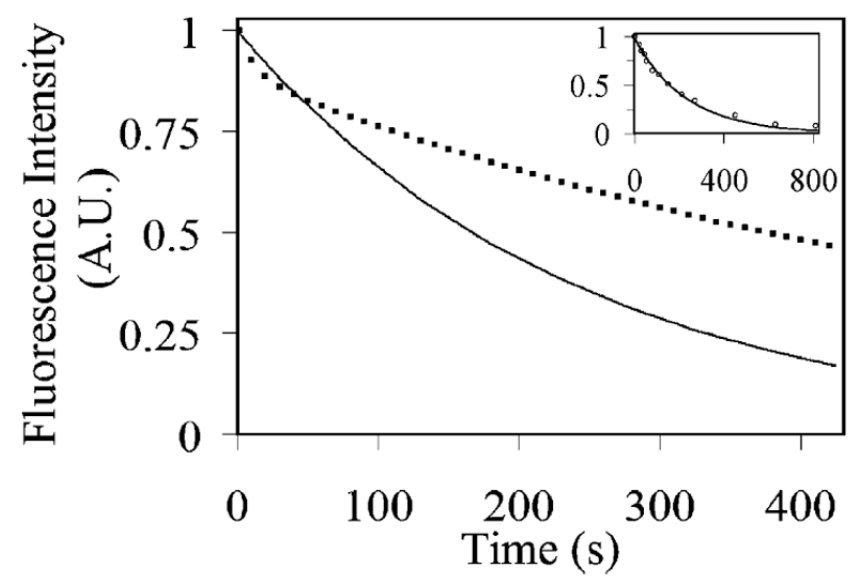

Figure 3. Comparative relaxation kinetics of the TBP-T*AdMLP ${ }_{\mathrm{dpx}}{ }^{*} \mathrm{~F}$ complex at $20{ }^{\circ} \mathrm{C}$ following a challenge with unlabeled duplex for the human (solid line) and yeast (broken line) proteins. The $h \mathrm{TBP}$ complex responds to addition of $\sim 1 \mu \mathrm{M}$ unlabeled DNA AdMLP with monophasic relaxation with $R=0.00417 \mathrm{~s}^{-1}$. In contrast, the $y \mathrm{TBP}$ complex yields sharply biphasic decay with $R_{1}=0.0766 \mathrm{~s}^{-1}(11 \%)$ and $R_{2}=0.00154 \mathrm{~s}^{-1}(89 \%)$, published previously $(18,47)$. Neither the $\boldsymbol{h T B P}$ nor $y$ TBP (18) complex is sensitive to the concentration of challenge DNA from 1 to $10 \mu \mathrm{M}$. The full $h \mathrm{TBP}$ relaxation curve from the global analysis (solid line) is shown in the inset together with the raw data (open circles). The reaction went to $\sim 95 \%$ completion, and the observed amplitude change was consistent with that from the equilibrium experiments. 

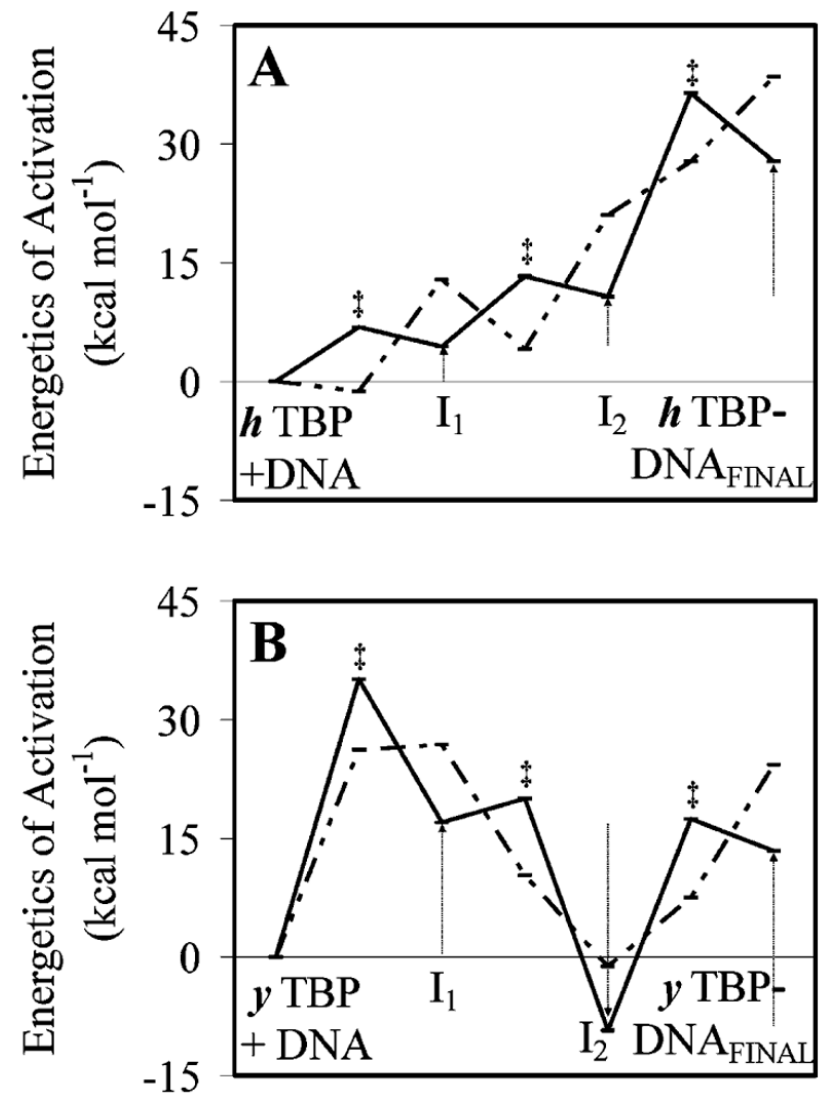

Figure 4. The energetic progression of the reaction from TBP $+\mathrm{DNA}_{\mathrm{AdMLP}}$ on the left to the most stable binary complex on the right for the human (A) and yeast (B) proteins at $25^{\circ} \mathrm{C}$. Differences in the energetics of the $h \mathrm{TBP}$ and $y$ TBP (18) reaction progressions are readily apparent from a graphic representation of $\Delta H^{\circ \neq}$ (solid line) and $T \Delta S^{\circ \neq}$ (dashed line). Both reactions are endothermic overall, with $\Delta H^{\circ}$ and $\Delta S^{\circ}$ values for $h \mathrm{TBP}$ of $27.8(23.8,31.8) \mathrm{kcal}$ $\mathrm{mol}^{-1}$ and $131.3(118,145) \mathrm{cal} \mathrm{K}^{-1} \mathrm{~mol}^{-1}$ and for $y \mathrm{TBP}, 13.4(11.6,15.2) \mathrm{kcal} \mathrm{mol}^{-1}$ and $81.3(76.6,86.6) \mathrm{cal} \mathrm{K}^{-1} \mathrm{~mol}^{-1}$ (18). These "overall" values represent the difference between the thermodynamic parameters for the final complex and free TBP + DNA. Because all three conformers are present at equilibrium, the observed change in such parameters is the difference between a weighted average of the three bound species and the corresponding value for the reactants; $\Delta H^{\circ}$ obtained from the van't Hoff analysis thus differs from the "overall" value shown in the figure [Table 1 (18)]. The modest activation energy of $7 \mathrm{kcal} \mathrm{mol}^{-1}$ required for the first $h \mathrm{TBP}$ transition (TBP $+\mathrm{DNA}_{\mathrm{AdMLP}} \rightarrow \mathrm{I}_{1}$ ) differs markedly from that of the $y$ TBP pathway, for which this step presents the largest energetic barrier with $\Delta H^{\circ \ddagger}=$ $35.1 \mathrm{kcal} \mathrm{mol}^{-1}$. The latter is overcome by a commensurate increase in entropy with $\Delta S^{\circ \ddagger}=87.8 \mathrm{cal} \mathrm{K}^{-1} \mathrm{~mol}^{-1}$, in contrast to the decrease in entropy in the course of h $\mathrm{I}_{1}$ formation with $\Delta S^{\circ \ddagger}=-4 \mathrm{cal} \mathrm{K}^{-1} \mathrm{~mol}^{-1}$. In the second partial reaction $\left(\mathrm{I}_{1} \rightarrow \mathrm{I}_{2}\right)$ the $h \mathrm{TBP}$ transformation repeats its pattern for the first step with a similar entropic gain and enthalpic loss. In contrast, the $y$ TBP partial reaction is strongly exothermic with a decrease in entropy, with $\Delta H^{\circ \ddagger}=3 \mathrm{kcal} \mathrm{mol}^{-1}$ and $\Delta S^{\circ \ddagger}=-55 \mathrm{cal} \mathrm{K}^{-1} \mathrm{~mol}^{-1}$. The result is that, whereas the ${ }^{\mathrm{h}} \mathrm{I}_{2}$ conformer is $6.3 \mathrm{kcal} \mathrm{mol}^{-1}$ higher in energy and 27.9 $\mathrm{cal} \mathrm{K}^{-1} \mathrm{~mol}^{-1}$ higher in entropy than ${ }^{\mathrm{h}} \mathrm{I}_{1}$, the corresponding thermodynamic changes in the $y \mathrm{TBP}$ reaction are $-26 \mathrm{kcal}$ $\mathrm{mol}^{-1}$ and $-94 \mathrm{cal} \mathrm{K}^{-1} \mathrm{~mol}^{-1}$, respectively. In the final transformation, ${ }^{\mathrm{h}} \mathrm{I}_{2}$ surmounts a substantial activation energy to become $h \mathrm{TBP}-\mathrm{AdMLP}_{\text {final }}$, aided by an accompanying increase in entropy, with $\Delta H^{\circ \neq}=25.7 \mathrm{kcal} \mathrm{mol}^{-1}$ and $\Delta S^{\circ \neq}$ $=23.1 \mathrm{cal} \mathrm{K}^{-1} \mathrm{~mol}^{-1}$, to achieve the largest energetic changes, with $\Delta H^{\circ}$ and $\Delta S^{\circ}$ values of $17.1 \mathrm{kcal} \mathrm{mol}^{-1}$ and $59.6 \mathrm{cal}$ $\mathrm{K}^{-1} \mathrm{~mol}^{-1}$. The final $y \mathrm{TBP}$ step is likewise entropically driven as the energetic losses associated with $\mathrm{yI}_{2}$ formation are overcome to form the final complex. The largest partial free energy change for $h \mathrm{TBP},-8.7 \mathrm{kcal} \mathrm{mol}^{-1}$, occurs in the initial binding step. ${ }^{\mathrm{h}} \mathrm{I}_{2}$ is $2.0 \mathrm{kcal} \mathrm{mol}{ }^{-1}$ lower in free energy than ${ }^{\mathrm{h}} \mathrm{I}_{1}$ whereas ${ }^{\mathrm{y}} \mathrm{I}_{2}$ is significantly less stable than ${ }^{\mathrm{y}} \mathrm{I}_{1}$. The corresponding equilibrium constant is thus $100 \times$ larger for the complex incorporating the human protein. Transition states are denoted $\left({ }^{\ddagger}\right)$, and arrows show progressive changes in $\Delta H^{\circ}$. 

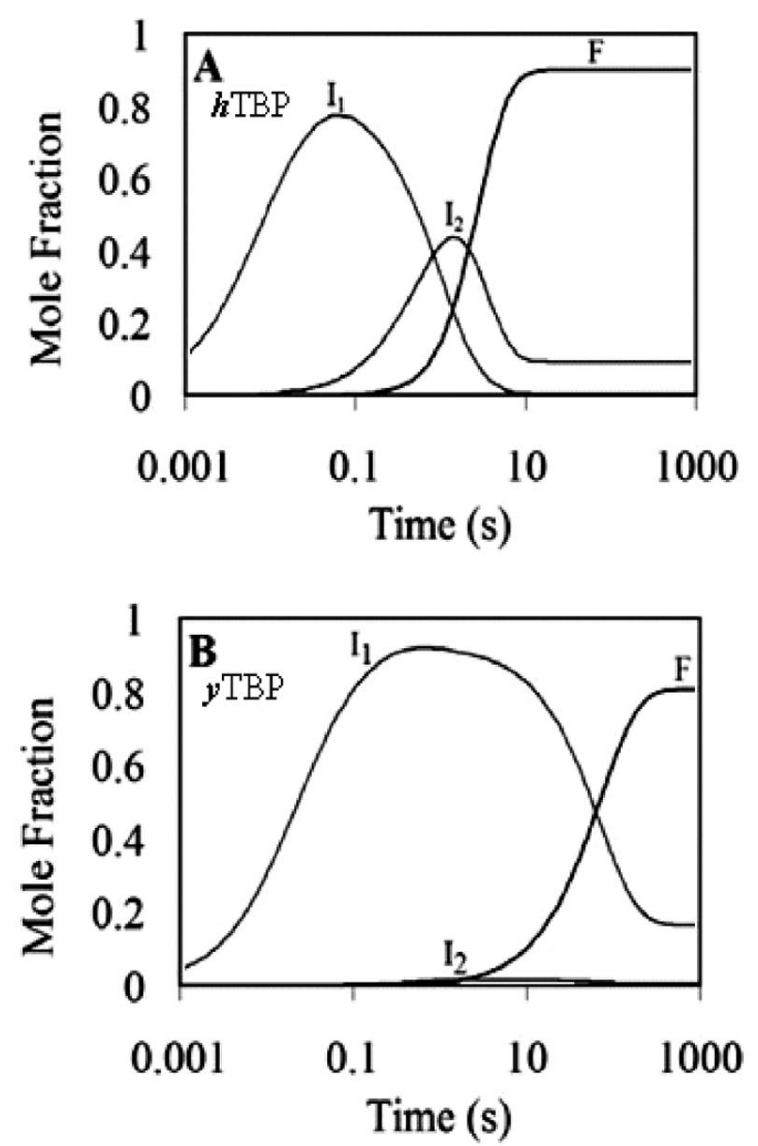

Figure 5. Comparison of the mole fractions of the $h$ TBP and $y$ TBP species at optimal in vivo temperatures. The timedependent populations of the three TBP-DNA ${ }_{\text {AdMLP }}$ species formed during association with the human protein at 37 ${ }^{\circ} \mathrm{C}(\mathrm{A})$ and the yeast protein at $30{ }^{\circ} \mathrm{C}(\mathrm{B})$ were simulated using $10 \mu \mathrm{M} \mathrm{DNA}_{\mathrm{AdMLP}}$ and $10 \mu \mathrm{M}$ protein and previously collected $y$ TBP data (18). The species-dependent differences are apparent in the rates of complex formation overall and in the comparative evolution of $\mathrm{I}_{1}, \mathrm{I}_{2}$, and the final conformer $(\mathrm{F})$ for each protein. 


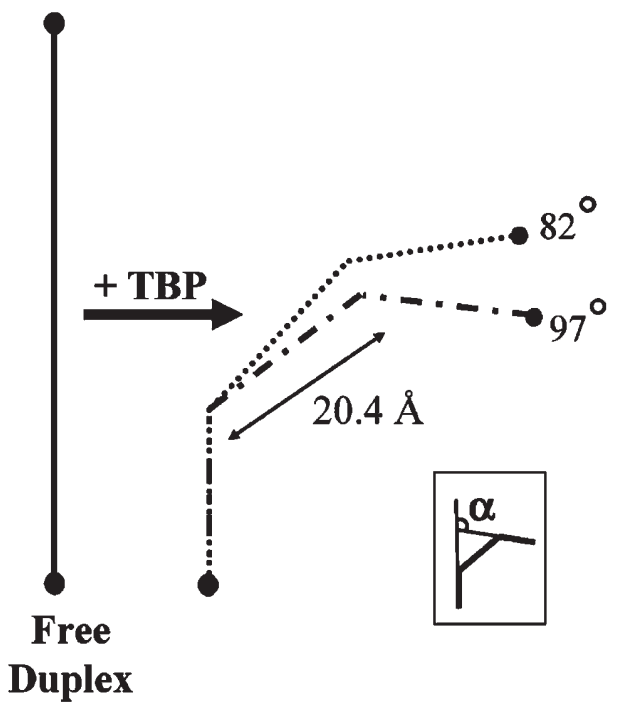

Figure 6. Comparative $\mathrm{T}^{*} \mathrm{AdMLP}_{\mathrm{dpx}}{ }^{*} \mathrm{~F}$ bending by $y \mathrm{TBP}_{\mathrm{wt}}$ (dotted line) and $\boldsymbol{h T B P} \mathrm{wt}_{\mathrm{wt}}$ (broken line). Time-resolved

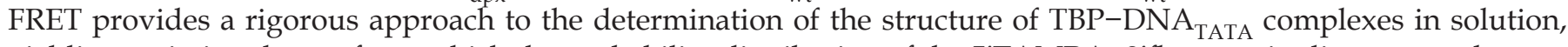
yielding emission decays from which the probability distribution of the 5'TAMRA-3'fluorescein distance can be precisely determined $(5,14-16,23,24)$. Further, the sensitivity of measurements at $\sim 60 \AA$ with this dye pair is such that a $1^{\circ}$ change in the bend angle results in a $1 \%$ change in the observed emission intensity. A high degree of confidence is thus ascribed to the difference measured for the $h \mathrm{TBP}$ and $y$ TBP induced bends, with the latter redetermined herein under identical conditions using $y \mathrm{TBP}$ prepared as described (22). $y$ TBP-bound $\mathrm{T}^{*} \mathrm{AdMLP}_{\mathrm{dpx}}{ }^{*} \mathrm{~F}$ has an $\overline{\mathrm{R}}=52.2 \AA$ with $\sigma=8.9 \AA$. Bend angles ( $\alpha$ ) were obtained from these data using a simple two-kink bending model $(5,14)$ and the method of moments (24).

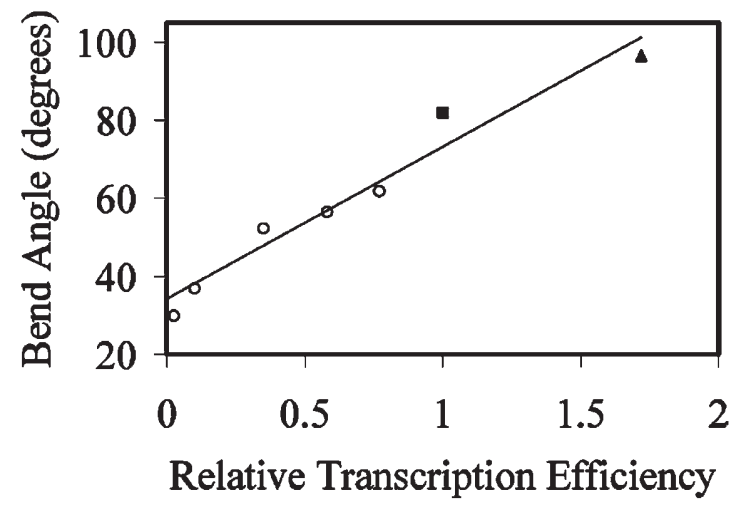

Figure 7. In vitro transcription efficiency (38) is strongly correlated with the degree of the TBP-induced bend for both the human and yeast proteins. Experimentally measured bends induced by $y$ TBP in AdMLP (solid square) and the A3, T6, C7, G6, and T5 AdMLP variant TATA sequences (open circles in order from bottom left) have been shown previously to correlate with both in vitro and in vivo transcription activity (5). The high relative transcription activity of $h \mathrm{TBP}-\mathrm{DNA}_{\mathrm{AdMLP}}, 172 \%$ (38), and the mean $h \mathrm{TBP}$-induced AdMLP bend angle of $97^{\circ}$ (solid triangle) extend this trend $\left(R^{2}=0.957\right)$. The $y \mathrm{TBP}-\mathrm{DNA}_{\mathrm{AdMLP}}$ bend angle was redetermined herein to ensure comparability. 